Rodolfo Andrade de Gouveia Vilela ${ }^{1}$

Eduardo Garcia Garcia ${ }^{2}$

Ildeberto Muniz de Almeida ${ }^{3}$

José Marçal Jackson Filho ${ }^{4}$

\section{A atuação do Estado e a saúde do trabalhador}

\author{
State action and worker's health
}

\footnotetext{
${ }^{1}$ Editor associado da RBSO. Faculdade de Saúde Pública da Universidade de São Paulo. São Paulo, SP, Brasil.

${ }^{2}$ Editor executivo da RBSO. Centro Técnico Nacional da Fundacentro. São Paulo, SP, Brasil.

${ }^{3}$ Membro do Conselho Editorial da RBSO. Universidade Estadual Paulista. Botucatu, SP, Brasil.

${ }^{4}$ Editor científico da RBSO. Centro Estadual do Rio de Janeiro da Fundacentro. Rio de Janeiro, RJ, Brasil.
}

O presente texto tem por finalidade restabelecer, reposicionar os leitores sobre possível equívoco de interpretação decorrente de trecho do nosso editorial publicado no último número (JACKSON FILHO et al., 2013), que trata da "aceitabilidade social" dos acidentes do trabalho e do inaceitável conceito de ato inseguro.

No mencionado trecho, agora excluído para evitar mal-entendidos (errata neste número), ao apreciarmos a ação do Estado, apoiamo-nos na recente tese de doutorado de Filgueiras (2012). Retiradas do contexto do trabalho referido e da maneira como foram apresentadas, as afirmativas podem induzir a uma generalização inadequada sobre a ação do Estado nessa questão. Essa possibilidade nos incita a refletir sobre a natureza da atuação do Estado, suas contradições, fissuras e brechas que possibilitam atuação em defesa da saúde dos trabalhadores, mesmo que em oposição a outras políticas hegemônicas que possam predominar no interior da ação estatal.

No campo da Saúde do Trabalhador, essa reflexão nos remete à importância da atuação do Ministério Público do Trabalho (MPT) como um dos atores do aparelho de Estado na defesa da saúde e da integridade dos trabalhadores. Sempre que a inação ou a omissão do Estado propiciam correlações assimétricas de forças na sociedade, a intervenção do MPT no cumprimento de seu papel constitucional de instituição garantidora da defesa dos direitos coletivos e individuais tem sido fundamental, como mostram muitos eventos marcantes no nosso campo que podem ser destacados - citamos alguns que vivenciamos de perto:

- A atuação histórica do MPT em parceria com entidades de trabalhadores, Centro de Referência em Saúde do Trabalhador de Campinas (Cerest-Campinas), auditores fiscais do Ministério do Trabalho e Emprego (MTE) e pesquisadores, que resultou na maior indenização já vista em nosso país, imputada às empresas Shell e Basf, responsáveis pela contaminação ambiental e da saúde de um grande contingente de trabalhadores em Paulínia-SP;

- A atuação do MPT articulada ao grupo móvel do MTE, Cerest(s) e Agentes da Vigilância em Saúde, que resultou na eliminação da prática corrente de terceirizações, coibição de situação degradante de alojamentos e outras condições precárias de trabalho e moradia dos trabalhadores canavieiros no Estado de São Paulo (MINAYO-GOMEZ, 2012); 
- O apoio político e institucional à atuação dos Cerest(s) para assegurar condição de independência e autonomia destes serviços municipais do Sistema Único de Saúde (SUS), ou como parceria em iniciativas e projetos de intervenção nas questões de saúde e segurança;

- O apoio a iniciativas de pesquisa com o estabelecimento de cooperação técnico-científica como as firmadas entre o MPT, a Universidade de São Paulo (Faculdade de Saúde Pública) e a Universidade Federal de Minas Gerais, assegurando condições para o desenvolvimento de estudos e pesquisas de interesse mútuo.

Por atuações como estas é que, no penúltimo parágrafo do referido editorial (JACKSON FILHO et al., 2013, p. 8), destacamos a atuação do MPT, que caminha em direção oposta à conciliação e à precarização das condições de trabalho:

a atuação de grupo de agentes públicos e de pesquisadores, a ação crescente do Ministério Público do Trabalho e da Advocacia Geral da União (por meio das ações regressivas) mostram que possibilidades concretas de mudanças estão surgindo.

Nas manifestações de junho de 2013, foi visto nas mãos de um jovem na Avenida Paulista um cartaz que dizia: “um novo mundo é possível”... Por entendermos o Estado como espaço de disputas complexas de forças e de interesses, acreditamos que os agentes públicos precisam ampliar e fortalecer seu leque de alianças, suas redes e conexões, e abranger de modo mais amplo a sociedade civil. Isso pode ser viável se conseguirmos disputar na sociedade uma nova cultura, novos consensos, novas utopias. Um caminho difícil, mas inevitável para quem sempre esteve no olho do furacão.

\section{Agradecimento}

À Mara Takahashi, pela reflexão proposta.

\section{Referências}

FILGUEIRAS, V. A. Estado e direito do trabalho no Brasil: regulação do emprego entre 1988 e 2008. 2012. $471 \mathrm{f}$. Tese (Doutorado em Ciências Sociais)-Faculdade de Filosofia e Ciências Humanas, Universidade Federal da Bahia, Salvador, 2012.

JACKSON FILHO, J. M. et al. Sobre a "aceitabilidade social” dos acidentes do trabalho e o inaceitável conceito de ato inseguro. Revista Brasileira de Saúde Ocupacional, São Paulo, v. 38, n. 127, p. 6-8, 2013.

MINAYO-GOMEZ, C. Produção de conhecimento e intersetorialidade em prol das condições de vida e de saúde dos trabalhadores do setor sucroalcooleiro. Ciência \& Saúde Coletiva, Rio de Janeiro, v. 16, n. 8, p. 3361-3368, 2011. 